\section{Finding a Fit: Biological Science Doctoral Students' Selection of a Principal Investigator and Research Laboratory}

Michelle A. Maher, ${ }^{\dagger *}$ Annie M. Wofford, ${ }^{\prime}$ Josipa Roksa, ${ }^{\S}$ and David F. Feldon ${ }^{\pi}$

'Division of Educational Leadership, Policy and Foundations, University of Missouri-Kansas City, Kansas City, MO 64110; ₹Graduate School of Education and Information Studies, University of California, Los Angeles, Los Angeles, CA 90095; \$Department of Sociology, University of Virginia, Charlottesville, VA 22904; 'Department of Instructional Technology \& Learning Sciences, Utah State University, Logan, UT 84322-2830

\begin{abstract}
In the laboratory-based disciplines, selection of a principal investigator (PI) and research laboratory (lab) indelibly shapes doctoral students' experiences and educational outcomes. Framed by the theoretical concept of person-environment fit from within a socialization model, we use an inductive, qualitative approach to explore how a sample of 42 early-stage doctoral students enrolled in biological sciences programs made decisions about fitting with a PI and within a lab. Results illuminated a complex array of factors that students considered in selecting a PI, including PI relationship, mentoring style, and professional stability. Further, with regard to students' lab selection, peers and research projects played an important role. Students actively conceptualized trade-offs among various dimensions of fit. Our findings also revealed cases in which students did not secure a position in their first (or second) choice labs and had to consider their potential fit with suboptimal placements (in terms of their initial assessments). Thus, these students weighted different factors of fit against the reality of needing to secure financial support to continue in their doctoral programs. We conclude by presenting and framing implications for students, PIs, and doctoral programs, and recommend providing transparency and candor around the $\mathrm{PI}$ and lab selection processes.
\end{abstract}

\section{INTRODUCTION}

In laboratory-based disciplines, doctoral education is shaped by faculty principal investigators (PIs), the research laboratories (labs) they lead, and the students who learn under the PIs' tutelage within their labs. For first-year doctoral students, selecting PIs to be their faculty advisors and labs in which to complete their doctoral training is paramount. Both PI and lab are necessarily intertwined, in that a student cannot select a PI without selecting that PI's lab. Further, this selection is a mutual process, in that the PI must agree to become the student's doctoral advisor and accept the student as a lab member. Thus, simultaneous selection of the "right" PI and lab, in terms of student compatibility, is critical to doctoral student success.

As Lee (2008) sagely stated, a doctoral advisor can "make or break a Ph.D. student" (p. 267). This is not surprising, as ideally, doctoral training acts as a cognitive apprenticeship in which the faculty member models, coaches, and scaffolds learning in a way that makes "visible and explicit those aspects of scholarly and professional expertise that are typically taken for granted and thus unarticulated" (Walker et al., 2008, p. 91). In this system, the PI is thought to interact closely with students to guide their development as disciplinary researchers (Austin, 2009; Maher et al., 2013a; Posselt, 2018). Within the contours of this apprenticeship as it occurs in lab-based disciplines, the research agendas of the PI and student are often tightly connected. Pragmatically, this apprenticeship fulfills PIs' need for students to staff their labs and generate scientific findings (Kyvik and Smeby, 1994; Dundar and Lewis, 1998; Lee and Bozeman, 2005)
Tammy Long, Monitoring Editor

Submitted Jun 3, 2019; Revised Apr 9, 2020 Accepted Apr 17, 2020

CBE Life Sci Educ September 1, 2020 19:ar31 DOI:10.1187/cbe.19-05-0105

*Address correspondence to: Michelle A. Maher (mahermi@umkc.edu)

(c) 2020 M. A. Maher et al. CBE-Life Sciences Education @ 2020 The American Society for Cell Biology. This article is distributed by The American Society for Cell Biology under license from the author(s). It is available to the public under an Attribution-Noncommercial-Share Alike 3.0 Unported Creative Commons License (http://creativecommons.org/licenses/ by-nc-sa/3.0)

"ASCB $®$ " and "The American Society for Cell Biology ${ }^{\prime}$ " are registered trademarks of The American Society for Cell Biology. 
and students' need for PI sponsorship to access funding and lab space essential for degree completion (Maher et al., 2019). Intellectually, this apprenticeship generates coauthored publications codifying scientific findings and nourishes the lines of investigation that flow between generations of scientists (Maher et al., 2013b; Campbell, 2003).

Students' selection of a research lab is arguably equally as critical as their selection of a PI, as "the research laboratory provides the basic substrate for effective research training" (Juliano and Oxford, 2001, p. 1010). The lab serves as the site in which students hone and apply specialized knowledge and skills, following the prevailing norms and values of their chosen scientific disciplines (Hunter et al., 2007; Holley, 2011; Szelényi et al., 2016). Students' participation in labs defines and shapes their emerging identities as scientists (Malone and Barabino, 2009; Lane et al., 2019). Additionally, lab placement typically defines the nature and scope of students' doctoral experiences by allowing them access to developmental networks of PIs, other faculty members, postdoctoral fellows, peers, and program administrators (Sweitzer, 2009; Ynalvez et al., 2017; Griffin et al. 2018). Over time, lab experiences also play a critical role in shaping tangible outcomes: research skill development (Feldon et al., 2019), publication authorship (Feldon et al., 2017), post-PhD career opportunities (Fuhrmann et al., 2011; Gibbs and Griffin, 2013), and doctoral student attrition (Conefrey, 1997; Maher et al., 2020). Thus, students' compatibility within a lab is essential to student success.

Despite the fundamental importance of students' PI and lab selection to subsequent student success within a range of labbased doctoral programs, little is known about how students, upon completion of lab rotations, make meaning of their compatibility with potential PIs and labs. Rotations, a common practice in many lab-based doctoral programs, are intended to facilitate student selection of a PI and lab (Arnaud, 2015; Dasgupta et al., 2015). These short-term lab experiences (usually between several weeks and one academic term) allow students to explore lab environments and research areas and engage with the PI who leads each lab. Not every lab-based doctoral program requires students to participate in rotations, and to our knowledge, no study to date has specified how widespread the rotation practice is among lab-based disciplines. However, our review of relevant literature locates rotations within advanced graduate training programs in biology (e.g., Conti and Liu, 2015), chemistry (e.g., Mendoza-Denton et al., 2017), medicine (Canver, 2012), and neuroscience (Barres, 2013), to name a few. Further, there are likely other lab-based disciplines in which at least some doctoral training programs use rotations, as the pedagogical practice of rotations is receiving greater attention for the benefits rotations can provide to incoming doctoral students. For example, a report from the National Academies of Sciences, Engineering, and Medicine's Committee on Revitalizing Graduate STEM Education in the 21st Century (2018) recently stated:

In the committee's judgment, one essential element of any $\mathrm{PhD}$ program is student access to a variety of research groups to allow them to grow their network of colleagues, to experience different types of research methods and working styles, and to ... "shop around" for a research topic and advisor(s) most suited to their intellectual interests ... this could mean rotations through several laboratories lasting from several weeks to a semester. (p. 115)
The end goal of rotation participation is for students to identify PIs whose research interests align with theirs and, by association, select labs in which they will complete their doctoral degrees (Holley, 2010). Thus, rotations both orient students to and establish them within the research labs that will become their intellectual homes during doctoral training (Conti and Liu, 2015). Securing a compatible PI as a doctoral advisor and successfully integrating into that PI's lab are critical tasks for early-stage doctoral students in the sciences (Golde, 1998). Our work (Maher et al., 2020) on early doctoral student attrition in the biological sciences squarely implicated lack of compatibility with PI and lab environment as a key contributor to students' decisions to leave their programs within the first two years of doctoral training.

Our further work on the experiences of early-stage doctoral training in the biological sciences (Maher et al., 2019) revealed that students can have widely varied rotation experiences, even among institutions that all have doctoral programs ranked in the top 50 of total research and development (R\&D) expenditures in biological sciences. First, as students selected labs for their rotations, students' experiences differed in terms of the extent to which they used and valued the formal (i.e., departmental and programmatic personnel) and informal information networks (i.e., rotating students as well as advanced students, postdocs, and others who worked within the labs). Second, as they considered their level of interest in available rotational labs, students' experiences varied in the extent to which they were open to the challenge of discovery and scientific diversity versus their need to stay within their preferred research topics. Third, students' experiences differed depending upon their willingness to engage PIs in discussions about the ongoing availability of funding and lab space if they joined a lab. Finally, within rotational labs, students' experiences differed depending on their need to prioritize their evolving scientific interests against each lab's social context. Given this array of experiences, we wondered how, when rotations ended, these doctoral students made decisions about fitting with a PI as well as a lab.

In the present study, we rely on two intersecting theories, person-environment fit and socialization, to explore the following research questions: 1) What factors do doctoral students consider when selecting a PI? 2) What factors do doctoral students consider when selecting a research laboratory? Our intent is to use study findings to provide guidance to students, PIs, and others involved in lab-based doctoral training in the sciences. We aim for these findings to facilitate candid and beneficial discussions underpinning students' successful selection of PIs and smooth transitions into the labs within which they will complete their doctoral work.

\section{THEORETICAL FRAMING}

Research investigating individuals' compatibility with their working environments, or person-environment fit, has a long history within management literature (e.g., Parsons, 1909; Pervin, 1968; Schneider, 1987) and vocational and counseling psychology (e.g., Holland, 1959, 1966, 1997; Nauta, 2010; Su et al., 2015). The concept of person-environment fit has even been applied to examine undergraduate students' compatibility with their educational environments (e.g., Feldman et al., 2004; Riggers-Piehl and Lehman, 2016). Only recently, however, has the concept been introduced into the doctoral education 
literature (Baker and Pifer, 2015). Kristof-Brown and Li (2017) state that successful person-environment fit generally refers to compatibility between the individual and the environment that occurs when the individual's needs are met by the environment and the demands of the environment are met by the abilities of the individual.

Person-environment fit is nested within and across multiple environmental levels, including person-vocation (compatibility between an individual and vocational choices), person-organization (compatibility between an individual and entire organization), person-job (compatibility between a person and a specific job), person-group (compatibility between an individual and immediate work group), and person-person (compatibility between a supervisor and subordinate; Jansen and Kristof-Brown, 2006). According to Su and colleagues (2015), three assumptions hold across all levels of fit conceptualizations. First, people seek environments that match their traits and abilities. Second, the extent to which people fit their work environments has significant consequences for both the individual and the environment. Finally, fit is an ongoing and reciprocal process in which people shape environments and environments shape people. As characterized by Kristof-Brown et al. (2018, p. 353), "individuals who experience good fit are more likely to engage in organizational citizenship behaviors." Thus, without sufficient individual affinity for the environment (i.e., perceived value similarity and liking) and exchange (i.e., transactions that, when successful, lead to future transactions that are more reciprocal and foster competence-based trust), students may withdraw from socialization.

\section{Conceptualizations of Fit}

Not surprisingly, given the many levels at which fit may occur and the many disciplines to which it has been applied, Kristof-Brown and Billsberry (2013) observe, "It has been suggested that there are as many ways to conceptualize and measure fit as there are scholars who study it" (p. 1). In an effort to clarify this conceptual and methodological confusion, they identify two distinct person-environment fit paradigms. In the first, a measure of fit is calculated by comparing an individual's self-reported data against data about the environment collected from that individual or others. However, the individual is never asked to report feelings or thoughts about his or her fit within the environment.

In the second paradigm, the individual's perceptions about fit within an environment are central. As Kristof-Brown et al. (2005) state, "Perceived fit ... is all done in the head of the respondents, allowing them to apply their own weighting scheme to various aspects of the environment. This permits ... salience of various dimensions to be captured in their ratings" (pp. 291-292). Kristof-Brown and Billsberry (2013) further contend that perceived fit has received scant attention in the literature, even though it is closest to individuals' decision making and most strongly linked to expected outcomes (e.g., job satisfaction).

We use perceived person-environment fit to explore doctoral students' perceptions of fit as they select a PI and a lab. Further, we use this framing to explore, as stated by Kristof-Brown et al. (2005) in the quote presented earlier, the internal weighting scheme students apply to various aspects of their fit with potential PIs and labs. Importantly, students' perceptions of fit have consequences; if students perceive their fit with PIs and labs as poor, their efforts to initiate or sustain personal and professional relationships with PIs and lab peers may wane, disconnecting them from the wide-ranging benefits of these relationships (Gopaul, 2016). Conversely, if they perceive their fit as strong, they will likely redouble their efforts to initiate or sustain these relationships. Therefore, we contend that-especially in lab-based disciplines in which labs are a critical facet of scholarly endeavor-understanding how perceived person-environment fit shapes PI and lab selection is crucial to understanding doctoral student engagement and success.

Person-Environment Fit within a Socialization Framework Socialization theory is the dominant framework for characterizing the mechanisms of doctoral preparation within the United States. Austin and McDaniels (2006, p. 400) define socialization as the "process of internalizing the expectations, standards, and norms of a given society, which includes learning the relevant skills, knowledge, habits, attitudes, and values of the group that one is joining." Accordingly, the socialization process for early-career PhD students is a joint process of socializing into both the role of doctoral student and membership within a specific discipline, with signature theories, methods, and standards for epistemic framing.

This process is typically characterized as progressing through a series of stages (Weidman et al., 2001): A student begins with naïve, anticipatory views of what the degree program and the conduct of science within the discipline will be like, then proceeds into formal interactions structured through course work and/or lab rotations. Following placement within a lab, students commence with socialization through informal interactions as a normative facet of supervised research and collaboration. Finally, students enter the personal stage, in which they begin to internalize the role of independent scholar, exercising more autonomy in the planning and execution of research that leads them through the defense of a dissertation and into a professional research role.

Prior research on students' progression through the stages of socialization does not provide much detail on the specific drivers and mechanisms that lead students to attain the benefits that theoretically stem from successful socialization. Much emphasis is placed on the quantity, quality, and diversity of interaction that students have with faculty and with their peers, which are expected to motivate the internalizing of academic and disciplinary cultural norms through knowledge acquisition, investment, and involvement (Weidman et al., 2001; Austin and McDaniels, 2006). However, past critiques have pointed out the apparent lack of agency that socialization typically grants students as independent actors and decision makers within their own academic lives (Tierney, 1994). Further, recent longitudinal studies of doctoral students in the biological sciences have failed to replicate this expected pattern (Feldon, 2020; Jeong et al., 2020; Roksa et al., 2018a,b).

Accordingly, we position student agency in assessing and responding to person-environment fit as a potential mechanism that underlies the broader descriptions of the socialization process. In both long-standing socialization theory and the specific lens of person-environment fit, the development of the student is a function of his or her engagement with the academic milieu. However, for socialization processes to have 
the opportunity to affect student development within and across stages, the student must determine that it is an environment in which he or she can be successful and wants to remain. Person-environment fit is a lens through which students can act as proactive agents in their own development, weighting different factors as they decide whether and how to engage with socialization contexts and opportunities. Thus, the acting of the milieu on the individual and the acting of the individual within the milieu are fully dependent on the extent to which students decide that they fit sufficiently enough to expect a productive endeavor. In this regard, socialization and person-environment fit assessments act as reciprocal processes. Elements of socialization must be opted into by the student (e.g., coauthorship, attending journal club meetings), and perceptions of affinity and exchange are shaped by the experiences of the student during socialization activity.

\section{METHODS}

To better understand how biology doctoral students interpret their experiences and make decisions about how to engage (or not) with their training environments, we employed an inductive, qualitative approach grounded in the premise that meaning is socially constructed by individuals in interaction with their worlds (Merriam, 2002). Specifically, we used semistructured, in-depth interviews to elicit students' perceptions and interpretations of their lived experiences (Merriam, 2009). Person-environment fit emerged as a focal theme from participants' reflections upon their experiences and sense-making that shaped their experiences as doctoral students.

\section{Sample and Data-Collection Procedures}

Nine geographically dispersed U.S. universities with biological science PhD programs (including microbiology, cellular and molecular biology, genetics, and developmental biology), all ranked in the top 50 of total $R \& D$ expenditures in biological sciences (National Science Foundation, 2014), were included in this study. Focusing on institutions with high R\&D is warranted, given that they present the ideal context in which to explore students' selection among many potential PIs and labs. In general, institutions with high R\&D have more extensive PI/lab options from which students can choose. In other contexts with limited R\&D expenditures, students may not have as many options, and thus may not be able to explore fit as much as simply trying to secure placement in a lab that has funding for them. Additionally, narrowing our institutional sample in this manner likely restricts variation in students' person-organization fit, allowing us to focus more closely on student perceptions of fit (i.e., mentor-mentee fit, research lab team-student fit) within environments that exert the most impact on doctoral education in this context. At each university included in this study, graduate students enrolled in biological science programs were required to participate in lab rotations in their first year of doctoral training. As noted earlier, lab rotations provide students with information about different PIs and lab contexts that they can use to make decisions regarding a lab they wish to join (Joy et al., 2015).

The $42 \mathrm{PhD}$ students who participated in this study across the nine universities were part of a larger longitudinal mixed-methods project studying students' experiences in doctoral education. To be included in this study, students must have agreed to participate in interviews about their doctoral experiences as part of the larger study. Demographic information for the sample is provided in Table 1 . Twenty-four (57\%) students identified as female. Fourteen (33\%) students identified as first generation. Twenty-four (57\%) students identified as white, while five identified as Asian or Asian American and one identified as Asian or Asian American/white. Twelve (29\%) students identified with racial/ethnic groups historically excluded in lab sciences, ${ }^{1}$ which included students who identified as Black or African American $(n=4)$, Black or African American/white $(n=1)$, Latino/Latina $(n=2)$, Latino/a/white $(n=3)$, American Indian/white $(n=1)$, and American Indian, Asian/Asian American, and Hawaiian $(n=1)$. Three participants identified as international students. At the time of doctoral program entry in Fall of 2014, students ranged in age from 21 to 33 years (mean $=24$ years; $S D=2.7$ years). We use pseudonyms for the student participants.

Once institutional review board (IRB) approval was received for the larger mixed-methods project, students were recruited to the project in two ways. First, program directors and department chairs for the 100 largest biological sciences doctoral programs in the United States were contacted by email to describe the study and request cooperation for informing incoming $\mathrm{PhD}$ students about the research project. Those who agreed forwarded recruitment information on behalf of the study to admitted students. In instances in which incoming cohorts were six students or more, campus visits were arranged for a member of the research team to present information to eligible students and answer questions during program orientation or an introductory seminar meeting. Second, emails describing student and eligibility criteria were forwarded to several Listservs, including those of the American Society for Cell Biology and the Center for the Integration of Research, Teaching, and Learning Network for broader dissemination. Those individuals who responded to recruitment emails or presentations were screened to ensure that they met the criteria for participation (i.e., beginning the first year of a $\mathrm{PhD}$ program in microbiology, cellular biology, molecular biology, developmental biology, or genetics in Fall 2014) and fully understood the expected scope of participation over the course of the funded project (four years with possible renewal). It was further explained that all data collected would remain confidential and that no information disseminated regarding the study would individually identify them in any way. Students signed consent forms per the requirements specified by the IRB for human subjects research at Utah State University. Students received a \$400 annual incentive, paid in semiannual increments.

The 42 students in this study were interviewed in the summer after completing their first year in their PhD programs. This interview occurred at a crucial point after students completed rotations and were making decisions about PIs and labs. This time point provided a unique window into how students perceived and evaluated their potential fit with PIs and within labs. With IRB approval, follow-up interviews were conducted during

\footnotetext{
${ }^{1}$ We use the term "historically excluded in the lab sciences" to refer to students identifying with racial/ethnic groups that have been severely marginalized, including Black or African American, Latino/a, American Indian, and Native Hawaiian. We use this terminology purposefully, as we believe the onus of exclusion to be on the institution rather than the student.
} 
TABLE 1. Description of participants $(n=42)$

\begin{tabular}{|c|c|c|c|c|}
\hline Pseudonym & Sex & Race/ethnicity & First generation & International \\
\hline Aaron & Male & White & $\mathrm{N}$ & $\mathrm{N}$ \\
\hline Adrian & Male & White & $\mathrm{Y}$ & $\mathrm{N}$ \\
\hline Amanda & Female & White & $\mathrm{N}$ & $\mathrm{N}$ \\
\hline Amelia & Female & White & $\mathrm{N}$ & $\mathrm{N}$ \\
\hline Ana & Female & Latina and white & $\mathrm{N}$ & $\mathrm{N}$ \\
\hline Antonia & Female & Latina and white & $\mathrm{N}$ & $\mathrm{N}$ \\
\hline Aria & Female & Asian/Asian American and white & $\mathrm{N}$ & $\mathrm{N}$ \\
\hline Avery & Female & White & $\mathrm{N}$ & $\mathrm{N}$ \\
\hline Blake & Male & White & $\mathrm{N}$ & $\mathrm{N}$ \\
\hline Byron & Male & White & $\mathrm{Y}$ & $\mathrm{N}$ \\
\hline Caleb & Male & White & $\mathrm{N}$ & $\mathrm{N}$ \\
\hline Chelsea & Female & Asian/Asian American & $\mathrm{Y}$ & $\mathrm{N}$ \\
\hline Claire & Female & White & $\mathrm{N}$ & $\mathrm{N}$ \\
\hline Colt & Male & White & & $\mathrm{N}$ \\
\hline Deanna & Female & White & $\mathrm{N}$ & $\mathrm{N}$ \\
\hline Elaine & Female & Black and white & $\mathrm{Y}$ & $\mathrm{N}$ \\
\hline Erica & Female & White & $\mathrm{N}$ & $\mathrm{N}$ \\
\hline Francisco & Male & Latino & $\mathrm{N}$ & $\mathrm{N}$ \\
\hline Gloria & Female & Asian/Asian American & $\mathrm{N}$ & $\mathrm{N}$ \\
\hline Hanh & Female & Asian/Asian American & $\mathrm{Y}$ & $\mathrm{N}$ \\
\hline Isabella & Female & White & $\mathrm{N}$ & $\mathrm{N}$ \\
\hline Jackson & Male & White & $\mathrm{Y}$ & $\mathrm{N}$ \\
\hline Janelle & Female & White & $\mathrm{Y}$ & $\mathrm{N}$ \\
\hline Jenna & Female & Black & $\mathrm{N}$ & $\mathrm{N}$ \\
\hline Joan & Female & White & $\mathrm{N}$ & $\mathrm{N}$ \\
\hline Josiah & Male & Black & $\mathrm{N}$ & $\mathrm{N}$ \\
\hline Landon & Male & White & $\mathrm{Y}$ & $\mathrm{N}$ \\
\hline Leah & Female & White & $\mathrm{Y}$ & $\mathrm{N}$ \\
\hline Levi & Male & White & $\mathrm{Y}$ & $\mathrm{Y}$ \\
\hline Luis & Male & Latino and white & $\mathrm{N}$ & $\mathrm{Y}$ \\
\hline Marina & Female & White & $\mathrm{Y}$ & $\mathrm{N}$ \\
\hline Mason & Male & American Indian and white & $\mathrm{N}$ & $\mathrm{N}$ \\
\hline Morgan & Female & Black & $\mathrm{N}$ & $\mathrm{N}$ \\
\hline Nigel & Male & Black & $\mathrm{Y}$ & $\mathrm{N}$ \\
\hline Nolan & Male & American Indian, Asian/Asian American, and Hawaiian & $\mathrm{Y}$ & $\mathrm{N}$ \\
\hline Otis & Male & Asian/Asian American & $\mathrm{N}$ & $\mathrm{Y}$ \\
\hline Ryan & Male & White & $\mathrm{Y}$ & $\mathrm{N}$ \\
\hline Sadie & Female & White & $\mathrm{N}$ & $\mathrm{N}$ \\
\hline Samantha & Female & White & $\mathrm{N}$ & $\mathrm{N}$ \\
\hline Violeta & Female & Latina & $\mathrm{N}$ & $\mathrm{N}$ \\
\hline Wen & Female & Asian/Asian American & $\mathrm{N}$ & $\mathrm{N}$ \\
\hline William & Male & White & $\mathrm{N}$ & $\mathrm{N}$ \\
\hline
\end{tabular}

the summer after their second year (i.e., following an academic year within a lab placement). This allowed us to consider how students experienced their first year in their selected labs and identify and explore cases in which a proper fit was not established.

Given the geographic dispersion of respondents, interviews were conducted via phone. Most interviews lasted 30-45 minutes, but some lasted almost an hour. The first author conducted $55(66 \%)$ of the phone interviews, while the second author conducted 17 (21\%); the remaining 11 (13\%) interviews were conducted by doctoral students who were part of the research team. In total, 83 interviews inform the current study (one year 1 interview was lost, but the student was retained in the study because her year 2 interview contained extensive information about her PI and lab selection experience). Year 1 and year 2 student interview protocols are provided in the Supplemental Material.

\section{Data Analysis}

Data analysis began with all transcripts being uploaded to Dedoose, a Web-based qualitative coding platform, where transcripts were analyzed by the first and second authors. Because all students in this study were also included in the earlier research study on lab rotations described earlier (Maher et al., 2019), both the first and second author were thoroughly familiar with all transcripts. Transcripts were analyzed using 
the constant comparative method (Glaser, 1965), in which interview data were compared and contrasted within and between transcripts, grounding initial interpretations in data. As we engaged with participants during interviews and subsequently reviewed transcripts, common framing emerged across participants' descriptions and explanations, reflecting substantial attention to how they perceived their fit with PIs (e.g., students' understanding of the PI role, their expectations for their selected PIs, how these expectations were developed, relationship with PI after selection) and labs (e.g., students' descriptions of their experience as they decided upon a lab to join, relations with potential lab mates before and after lab selection, description of research interests). Iterative refinement of these emergent trends yielded distinct categories of meaning through open coding methods (i.e., "breaking apart and delineating concepts to stand for interpreted meaning of raw data," Corbin and Strauss, 2015, p. 239). The first and second author met to compare initial coding results and resolve differences. To further refine the codes, the first author created and shared memos and diagrams designed to tease out intricacies within participant cases and discrete codes as well as to discover the larger pattern across the data.

The first and second author created a codebook designed to be flexible throughout the coding process. The first author used this codebook to open code all remaining transcripts (Corbin and Strauss, 2015). After open coding was complete, the first author undertook axial coding, a strategy in which "categories are related to their subcategories to form more precise and complete explanations" (Strauss and Corbin, 1998, p. 24), to identify overarching themes within perceived PI fit, perceived lab fit, and the interconnections between these themes. The second author then closely reviewed the first author's axial coding decisions and discussed discrepancies in interpretations with the first author until a resolution was reached. To further increase trustworthiness of interpretation, the second author closely reviewed the resulting unified story and interpretations supporting it to ensure that they recognizably reflected and plausibly explained independently observed patterns within the data. From our phone conversations with these students, we sensed that many felt highly pressed for time in their demanding schedules; thus, we decided not to add an additional burden to their workload by asking them to give further of their time for member checking, a technique for respondent validation to increase trustworthiness of data collection and interpretation.

\section{Limitations}

While this study is positioned to make inroads toward better understanding the constellation of factors that biological sciences doctoral students consider in their PI and lab selections, some inherent limitations are worth noting. First, investigating the top R\&D institutions is a strength, as it provides insights into doctoral students' experiences at well-resourced institutions. Presumably, these institutions may offer some of the best circumstances in terms of providing students with resources and structural support for selecting and thriving in research labs. However, it is a notable limitation that the results of this study do not speak to a broad institutional sample, and future research should seek to understand the lab selection process in a variety of institutional contexts (e.g., comprehensive universities, minority-serving institutions).
Additionally, our study is situated in a specific disciplinary context (i.e., biological sciences) that does not necessary generalize to other programs or fields. Yet, we posit that these emergent themes discussing the doctoral students' faculty advisor selection process may be applicable, even if an institutional training model does not include rotations as a basis for informing such decisions. Third, the narrow scope and sample size for this study limited our ability to draw summative conclusions about how students holding historically excluded social identities in the sciences (e.g., by race/ethnicity, gender, first-generation status) navigated the lab and PI selection process compared with their well-represented peers. When possible, we have included some insight into demographic trends in the results; however, we believe that each of these nuanced trends warrants its own in-depth examination beyond the scope of this paper.

\section{Positionality}

As this was a qualitative study guided by a constructivist interpretation, it is important for us to note our positionality. Our personal epistemologies and lenses as researchers informed our approach throughout this study. Three of the authors are established faculty in social sciences disciplines and advise $\mathrm{PhD}$ students, and one of the authors is a current $\mathrm{PhD}$ student in a social sciences discipline. None of the authors work directly in a scientific environment, yet all of the authors have had extensive exposure to the sciences through research or practice. Additionally, we recognize that our own social identities (three of the authors are women and all authors identify as white) may have influenced our approach to data collection and analyses.

\section{RESULTS}

The present study explored two research questions: 1) What factors do doctoral students consider when selecting a PI? 2) What factors do doctoral students consider when selecting a research laboratory? Our results illuminate a complex array of considerations students weigh as they select a PI, as well as the important role of peers and research projects in selecting a lab. Although we parse these considerations for analytic clarity, as noted earlier, the PI and lab are necessarily intertwined, and both are critical to doctoral student success. The final section explores what happens when fit is not achieved-that is, the factors related to students leaving their PIs and labs.

\section{Fit with the PI}

Doctoral students' "fit" with a PI was unequivocally salient for the participants in our study, and Jackson summed up the importance of the PI decision-making process well in saying, "The [PI] decision is probably one of the biggest decisions of a doctoral student's life. They are mentoring you for five years, helping you get your job afterwards, and you're also working on publications [with them] after you leave." We identified three dominant factors students used to determine PI fit, which included their relationships with their PIs, PI mentorship style, and PI professional stability. Every student in our study mentioned at least one of these three factors.

PI Relationship. Thirty-five (83\%; 20 female students, nine students historically excluded in the lab sciences, 11 first-generation students) recognized the need to select a PI with whom they had a relationship that had strong potential to remain 
TABLE 2. Frequencies of students' discrete social identities by emergent theme $(n=42)$

\begin{tabular}{|c|c|c|c|c|c|}
\hline & \multicolumn{5}{|c|}{ Percent (and count) of students within theme } \\
\hline & $\begin{array}{c}\text { Relationship } \\
\text { with PI }\end{array}$ & $\begin{array}{l}\text { Mentoring } \\
\text { style of PI }\end{array}$ & $\begin{array}{l}\text { PI professional } \\
\text { stability }\end{array}$ & $\begin{array}{c}\text { Research } \\
\text { project }\end{array}$ & $\begin{array}{c}\text { Lab } \\
\text { mates }\end{array}$ \\
\hline \multicolumn{6}{|l|}{ Gender } \\
\hline Men $(n=18)$ & $\begin{array}{c}83 \% \\
(n=15)\end{array}$ & $\begin{array}{c}83 \% \\
(n=15)\end{array}$ & $\begin{array}{c}44 \% \\
(n=8)\end{array}$ & $\begin{array}{c}67 \% \\
(n=12)\end{array}$ & $\begin{array}{c}72 \% \\
(n=13)\end{array}$ \\
\hline Women $(n=24)$ & $\begin{array}{c}83 \% \\
(n=20)\end{array}$ & $\begin{array}{c}92 \% \\
(n=22)\end{array}$ & $\begin{array}{c}42 \% \\
(n=10)\end{array}$ & $\begin{array}{c}79 \% \\
(n=19)\end{array}$ & $\begin{array}{c}63 \% \\
(n=15)\end{array}$ \\
\hline \multicolumn{6}{|l|}{ Race/ethnicity } \\
\hline White, Asian, or Asian-American students $(n=30)$ & $\begin{array}{c}87 \% \\
(n=26)\end{array}$ & $\begin{array}{c}90 \% \\
(n=27)\end{array}$ & $\begin{array}{c}40 \% \\
(n=12)\end{array}$ & $\begin{array}{c}80 \% \\
(n=24)\end{array}$ & $\begin{array}{c}67 \% \\
(n=20)\end{array}$ \\
\hline Historically excluded students in lab sciences $(n=12)$ & $75 \%(n=9)$ & $\begin{array}{c}83 \% \\
(n=10)\end{array}$ & $\begin{array}{c}50 \% \\
(n=6)\end{array}$ & $\begin{array}{c}67 \% \\
(n=8)\end{array}$ & $\begin{array}{c}58 \% \\
(n=7)\end{array}$ \\
\hline \multicolumn{6}{|l|}{ Generation status } \\
\hline First generation $(n=14)$ & $\begin{array}{c}79 \% \\
(n=11)\end{array}$ & $\begin{array}{c}86 \% \\
(n=12)\end{array}$ & $\begin{array}{c}36 \% \\
(n=5)\end{array}$ & $\begin{array}{c}64 \% \\
(n=9)\end{array}$ & $\begin{array}{c}57 \% \\
(n=8)\end{array}$ \\
\hline Continuing generation $(n=28)$ & $\begin{array}{c}86 \% \\
(n=24)\end{array}$ & $\begin{array}{c}89 \% \\
(n=25)\end{array}$ & $\begin{array}{c}46 \% \\
(n=13)\end{array}$ & $\begin{array}{c}79 \% \\
(n=22)\end{array}$ & $\begin{array}{c}71 \% \\
(n=20)\end{array}$ \\
\hline
\end{tabular}

positive and productive over time. As Jenna advised, "It makes a lot of sense for both parties to be happy." Violeta added, "I'm not saying you have to be BFFs (best friends forever) with your advisor, but it's very important for you guys to have a good relationship." For students, a "good relationship" with the PI included a sense of authenticity ("It's most important to me that [my PI] is a real human being," Adrian), comfort ("We can be casual with each other and we can joke around," Aria), communication ("I thought I could work with my PI really well, that we could communicate," Chelsea), respect ("She [my PI] is so respectful to her students," Marina) and interest ("I felt like he [my PI] would really take an interest in me"; Colt). For two students, their PIs' openness to career aspirations outside academia contributed to their PI choice ("My PI is comfortable with my future goals, which are not being a professor," Jackson; "I don't want a traditional academic ramp. Having a PI who is will to accommodate that is a really big deal for me," Sadie).

Our analysis of student response frequencies within the PI relationship category revealed roughly equally high percentages within students' discrete social identities (Table 2) and intersecting social identities (Table 3). This suggests that students' perceived PI relationships were important for students regardless of sociodemographic background. However, we did find two students (Janelle and Marina), both first-generation women, who made it clear that they were grateful to have selected women as their PIs and mentors. Janelle recalled, "I'm glad that I have a female mentor. I wish I had rotated with more of them, because that is something that was important to me and I didn't realize it at the time."

PI Mentoring Style. Rotation participation introduced students to PIs who provided a direct, "hands-on" mentoring style, an indirect, more student-independent "hands-off" style, or an "ad hoc" style in which they were available to students as needed. Thirty-seven students (88\%) indicted that PI mentorship style was an important factor in their considerations of their PI selections. Of these, 14 (10 female students, three students historically excluded in the lab sciences, seven first-generation students) preferred a hands-on mentoring style in which the faculty member was actively involved and accessible in students' everyday lives. Aria described her thinking about such a mentoring style by stating:

Personally, I like a little bit more hands-on mentorship. I'd like to be able to talk to the PI about problems and not worry about them getting mad at me ... I feel like I can bring up ideas to him [my PI], and then ask him for feedback on my output. He's always been very supportive.

Eleven (seven female students, two students historically excluded in the lab sciences, three first-generation students) preferred an ad hoc mentoring style, which our participants' reflections suggested to be a combination of PIs' active involvement and fostering of doctoral students' independence. This style of mentorship was described well by Ana, who stated, "I just barge into my PI's office when I need to talk ... and we meet about once a month. I've been pretty independent, but I like that." Thus, for some students, the ad hoc mentoring style provided the support they desired coupled with the agency to be fairly autonomous in the lab.

Finally, seven (three female students, four students historically excluded in the lab sciences, one first-generation student) preferred a hands-off style, which was described among our participants as a style that allowed for a high amount of individual agency and independence in lab work. As a proponent of a hands-off style, Jenna stated, "My relationship with my PI is pretty hands-off. My PI is always traveling, so one-on-one meetings are rare; we communicate by email. She gives me freedom to basically explore. For me, it's ideal because I don't feel restricted." For students such as Jenna who sought agency and independence, the hands-off PI mentoring style was ideal.

Of note, three students stated that they selected a PI based, in part, on an anticipated mentoring style (hands-on or ad hoc), but when they actually joined the labs, they found their PIs to be hands-off. In these cases, they had to compromise. As Byron explained, "The PI [I chose] is a little bit more hands-off than I would like, but you can't have everything, sometimes. My PI got a lot busier since I rotated, so he's been around a lot less." 
TABLE 3. Frequencies of students' intersecting social identities by emergent theme $(n=42)$

\begin{tabular}{|c|c|c|c|c|c|}
\hline & \multicolumn{5}{|c|}{ Percent (and count) of students within theme } \\
\hline & $\begin{array}{l}\text { Relationship } \\
\text { with PI }\end{array}$ & $\begin{array}{l}\text { Mentoring } \\
\text { style of PI }\end{array}$ & $\begin{array}{l}\text { PI professional } \\
\text { stability }\end{array}$ & $\begin{array}{c}\text { Research } \\
\text { project }\end{array}$ & $\begin{array}{c}\text { Lab } \\
\text { mates }\end{array}$ \\
\hline \multicolumn{6}{|l|}{ Race/ethnicity + gender } \\
\hline White, Asian, or Asian-American men $(n=12)$ & $\begin{array}{c}92 \% \\
(n=11)\end{array}$ & $\begin{array}{c}83 \% \\
(n=10)\end{array}$ & $\begin{array}{c}42 \% \\
(n=5)\end{array}$ & $\begin{array}{c}75 \% \\
(n=9)\end{array}$ & $\begin{array}{c}75 \% \\
(n=9)\end{array}$ \\
\hline White, Asian, or Asian-American women $(n=18)$ & $\begin{array}{c}83 \% \\
(n=15)\end{array}$ & $\begin{array}{c}94 \% \\
(n=17)\end{array}$ & $\begin{array}{c}39 \% \\
(n=7)\end{array}$ & $\begin{array}{c}83 \% \\
(n=15)\end{array}$ & $\begin{array}{c}61 \% \\
(n=11)\end{array}$ \\
\hline Historically excluded men in lab sciences $(n=6)$ & $\begin{array}{c}67 \% \\
(n=4)\end{array}$ & $\begin{array}{c}83 \% \\
(n=5)\end{array}$ & $\begin{array}{c}50 \% \\
(n=3)\end{array}$ & $\begin{array}{c}67 \% \\
(n=4)\end{array}$ & $\begin{array}{c}67 \% \\
(n=4)\end{array}$ \\
\hline Historically excluded women in lab sciences $(n=6)$ & $\begin{array}{c}83 \% \\
(n=5)\end{array}$ & $\begin{array}{c}83 \% \\
(n=5)\end{array}$ & $\begin{array}{c}50 \% \\
(n=3)\end{array}$ & $\begin{array}{c}67 \% \\
(n=4)\end{array}$ & $\begin{array}{c}50 \% \\
(n=3)\end{array}$ \\
\hline \multicolumn{6}{|l|}{ Generation status + gender } \\
\hline First-generation men $(n=8)$ & $\begin{array}{c}75 \% \\
(n=6)\end{array}$ & $\begin{array}{c}75 \% \\
(n=6)\end{array}$ & $\begin{array}{c}38 \% \\
(n=3)\end{array}$ & $\begin{array}{c}50 \% \\
(n=4)\end{array}$ & $\begin{array}{c}50 \% \\
(n=4)\end{array}$ \\
\hline First-generation women $(n=6)$ & $\begin{array}{c}83 \% \\
(n=5)\end{array}$ & $\begin{array}{l}100 \% \\
(n=6)\end{array}$ & $\begin{array}{c}33 \% \\
(n=2)\end{array}$ & $\begin{array}{c}83 \% \\
(n=5)\end{array}$ & $\begin{array}{c}67 \% \\
(n=4)\end{array}$ \\
\hline Continuing-generation men $(n=10)$ & $\begin{array}{c}90 \% \\
(n=9)\end{array}$ & $\begin{array}{c}90 \% \\
(n=9)\end{array}$ & $\begin{array}{c}50 \% \\
(n=5)\end{array}$ & $\begin{array}{c}80 \% \\
(n=8)\end{array}$ & $\begin{array}{c}80 \% \\
(n=8)\end{array}$ \\
\hline Continuing-generation women $(n=18)$ & $\begin{array}{c}83 \% \\
(n=15)\end{array}$ & $\begin{array}{c}89 \% \\
(n=16)\end{array}$ & $\begin{array}{c}44 \% \\
(n=8)\end{array}$ & $\begin{array}{c}78 \% \\
(n=14)\end{array}$ & $\begin{array}{c}61 \% \\
(n=11)\end{array}$ \\
\hline \multicolumn{6}{|l|}{ Generation status + race/ethnicity } \\
\hline First-generation white, Asian, or Asian-American students $(n=11)$ & $\begin{array}{c}81 \% \\
(n=9)\end{array}$ & $\begin{array}{c}91 \% \\
(n=10)\end{array}$ & $\begin{array}{c}27 \% \\
(n=3)\end{array}$ & $\begin{array}{c}73 \% \\
(n=8)\end{array}$ & $\begin{array}{c}64 \% \\
(n=7)\end{array}$ \\
\hline First-generation historically excluded students in lab sciences $(n=3)$ & $\begin{array}{c}67 \% \\
(n=2)\end{array}$ & $\begin{array}{c}67 \% \\
(n=2)\end{array}$ & $\begin{array}{c}67 \% \\
(n=2)\end{array}$ & $\begin{array}{c}67 \% \\
(n=2)\end{array}$ & $\begin{array}{c}33 \% \\
(n=1)\end{array}$ \\
\hline Continuing-generation white, Asian, or Asian-American students ( $n=19)$ & $\begin{array}{c}89 \% \\
(n=17)\end{array}$ & $\begin{array}{c}89 \% \\
(n=17)\end{array}$ & $\begin{array}{c}47 \% \\
(n=9)\end{array}$ & $\begin{array}{c}84 \% \\
(n=16)\end{array}$ & $\begin{array}{c}84 \% \\
(n=16)\end{array}$ \\
\hline Continuing-generation historically excluded students in lab sciences $(n=9)$ & $\begin{array}{c}78 \% \\
(n=7)\end{array}$ & $\begin{array}{c}89 \% \\
(n=8)\end{array}$ & $\begin{array}{c}44 \% \\
(n=4)\end{array}$ & $\begin{array}{c}67 \% \\
(n=6)\end{array}$ & $\begin{array}{c}67 \% \\
(n=6)\end{array}$ \\
\hline
\end{tabular}

Although these three categories (hands-on, ad hoc, and hands-off) applied to the ways in which many of the students in our study envisioned their PI's mentoring style, five (two female students, one student historically excluded in the lab sciences, no first-generation students) offered PI mentoring style descriptions we could not classify within these constructs. For example, Aaron said he wanted to find a PI who would lead him well in his scientific journey, but he did not show any particular preference as to the PI's day-to-day mentorship style that would contribute to this end goal. Our analysis of student response distribution across categories (hands-on, ad hoc, hands-off, not classifiable) by students' discrete social identities (see Table 2) and students' intersecting social identities (see Table 3) suggests that women and first-generation students appeared somewhat more likely to prefer a hands-on PI mentoring style-a nuanced difference that warrants further research.

PI Professional Stability. In comparison to PI relationship and PI mentoring style, noticeably fewer students ( $n=18 ; 43 \%$ ), regardless of social identities (Tables 2 and 3), considered PI professional stability, which included level of funding and years of faculty experience. Of these, 12 (67\%; six female students, five students historically excluded in the lab sciences, three first-generation students) recognized the need for PIs to have available funding to support them if they joined that PI's lab. As Colt stated, "You can join a lab without funding, but then it's a struggle to do research. You basically have to write off a year of your $\mathrm{PhD}$ just trying to write grants and get funding to do your research." Regardless, some students and PIs were willing to (or needed to) take that chance. As Leah recounted:

To get accepted [into the lab I chose], my PI had to have a grant come through. Most other labs taking students already had solid funding, so I was a little bit up in the air if I could join until that grant came in. Luckily it did, even though it was last minute.

Six (14\%; three female students, two students historically excluded in the lab sciences, two first-generation students) also considered the PI's years of faculty experience. As Aaron recalled, "I wanted a PI that was reputable in the field, preferably one that was already a full professor." Other students, however, selected an untenured PI, but not without recognizing the associated risks. Elaine recounted, "I did have some concerns about her [the PI she selected] because she is a new faculty member. They [other faculty] said not to worry because she is a great scientist." In constrast, Ryan stated:

I worry since he [PI] is a junior faculty. In fact, a PI I worked with for my first rotation actually went through the tenure process this past year and she didn't get it, to the surprise of many people. That set in a little bit of fear this past spring and winter. I was like, "Oh no. If she couldn't get it that means anything can happen." He just submitted his package and we won't find out [if he receives tenure] until next spring. 
Thus, presented findings indicate that students recognized and considered a range of factors as they determined their fit with a PI, including the nature of the relationship with the PI, PI mentoring style, and PI professional stability. Of these, relationship and mentoring style were dominant, while professional stability remained in the background for many students.

\section{Fit with the Lab}

Just as students were aware of the importance of the PI choice, they were aware of the importance of their choice of a lab. The PI is not the only person in the lab, and our participants emphasized the key role that their prospective lab mates would have in shaping their day-to-day lives in the lab. In addition, many students noted and attempted to understand how the specific science in the lab would underscore their doctoral experiences and how their evolving interests would fit in the lab.

Lab Mate Fit. When selecting a lab, finding a fit with lab mates was important to a significant number of students $(n=28$, or 67\%; 15 female students, seven students historically excluded in the lab sciences, eight first-generation students). As with PI selection, students recognized that their lab selection was a long-term commitment, evidenced by Aria musing, "Am I going to be happy going into the lab every day for the next five years? That's where the people play a large role." Students wanted collegial, supportive relationships with lab mates, such as Luis, who recalled, "I think that people [in the lab] had a lot of impact in my decision [to join a lab], if I felt welcomed there in terms of [how] people liked each other. I feel that is why I ended up joining my lab." Further, students understood that positive relationships with lab mates were essential to their productivity in the lab. As Hanh advised, "They [lab mates] can help you, especially with the techniques you need for your project. You need to be on good terms with them." Notably, in our analyses of this theme by students' social identities, we observed that fewer first-generation and historically excluded students emphasized lab mate fit (Table 2). However, these differences should be interpreted with caution due to small sample sizes.

Research Project Fit. As noted earlier, all students in our study participated in lab rotations during their first years of doctoral study. In each, they had the opportunity to learn about the research conducted in the lab. Thirty-one $(75 \% ; 18$ female students, nine students historically excluded in the lab sciences, nine first-generation students) considered their fit with the research conducted in rotational labs as a key lab section criterion. Some realized that the research conducted in a rotation lab was not a fit for them, such as Colt, who recalled, "It just turned out that I didn't want to do that specific type of research. It was nothing about them [the PI and lab mates of that lab]." Others discovered unanticipated, emergent research interests that swayed their selection of a lab, such as Leah, who stated:

My advice [to those selecting a lab] would be to try things you've never done before, because you might end up enjoying it. That's what happened to me. I never thought I would be in the lab and doing what I am doing, but I really, really enjoy it.
Besides their interest in the research conducted in the labs they had selected, some students considered additional research-related issues, such as project time, and their opinions of such sometimes conflicted. This was the case with Claire and Isabella, who both had the opportunity to join new projects. Claire had reservations about such a new project, stating that:

One reason I didn't end up joining [a specific lab] is because everything was so new, I had much less comfort that I would finish in a timely manner. If you're still setting everything up and feeling your way through, you run the risk of it taking you a year or two just to get your bearings. That was less appealing.

On the other hand, Isabella was energized by the freedom that joining a new project would allow her. She related:

There was this opening on this project that no one had started yet, so I was able to make it my own. That contributed a lot to me choosing that lab because I could visualize what my thesis would be at the beginning, which is important to me because I don't want to waste time or dawdle in graduate school. I want to get things done and move on to the next step.

Josiah also shared Isabella's sentiment of wanting to use research project opportunities to strategically prepare for longer-term career goals. He stated, "For me, when making this decision, it was pretty much 'Okay, what do I want to do? Which lab will get me to that end destination with the best skills and connections and collaborations?"'

When we evaluated how students' demographic backgrounds may relate to their emphasis on research project fit, Tables 2 and 3 illustrate roughly equal percentages across students' social identities. This suggests that perceived fit with the research project was equally important for students regardless of sociodemographic background.

Across both subthemes related to finding a lab fit, our participants recognized that finding an environment amenable to their working styles and interests was integral to their success as doctoral students. With regard to the importance of this choice, Josiah memorably stated:

Choosing a permanent lab home in graduate school is probably one of the most important decisions you make for the rest of your life, besides what graduate school you go to and what spouse you decide to marry. It very much impacts future career opportunities, people you may postdoc with, what field you choose to pursue after your research, what field you land in and specialize in. It very much is a huge decision.

\section{Not Finding a Fit}

At the time of the second interview, the summer after students' second academic years, all students had joined a lab. Most reported being satisfied with their choices of PI and lab. However, five students at four different institutions in the study reported that they had left the first lab they had joined. One student left the first lab after just two months, whereas a few others stayed in their first labs as long as 12 months. Although these students represent a small percentage of the sample, we 
elect to share their stories, because they provide unique insights into the struggles that accompanied the effort of some students to find a fit in their doctoral programs. We highlight each student's story within thematic similarities, although we acknowledge that each student experienced unique circumstances that played a role in not finding fit.

Three students' stories about the reasons they left their labs revealed structural problems related to funding, which is integral to doctoral students' long-term stability and success. Aaron, a white, continuing-generation man, initially chose a lab based on his interests and the lab environment but reflected:

There was an initial falling out with serious miscommunication on the professor's behalf to me about their ability to support me being a student in that lab. I was not being paid, and that came to the attention of the department. After some investigation, it turned out that I was not able to maintain my position in that lab, because the professor did not have the appropriate funding to support me.

After discovering that he could not be funded in his lab, Aaron was asked to complete an additional rotation in what was then his second year. After rotating with a faculty member who heard about his situation, Aaron believed that his new placement worked out for the better.

Similarly, Erica did not explicitly factor funding into her initial lab decision. Erica, who identified as a white, continuing-generation woman, also looked for markers of stability as well as an amicable environment, but recalled:

Now, looking back, I wish I had factored in funding more. Because I knew that he [my first PI] didn't have any external grants when I joined the lab. I thought that he would win a grant in the next year, but he didn't. If I had been a bit wiser, I might not have chosen that lab. I'm still rotating, but it [my current rotation lab] is basically my best option, so I'm going to join even though it's not quite as comfortable of a fit as my previous lab. It's got a good project and they've got funding, so that is my new lab.

At the time of her second interview, Erica had only been in her new lab for just over a month. She stood by her decision to factor in lab environment in the selection process, but she also acknowledged that "sometimes it's more important to think about the money."

Morgan, a Black woman who identified as a continuing-generation student, was the only student in the historically excluded in the lab sciences category among our participants who did not find a fit in the first lab. Again, this lack of fit was due to funding, and Morgan noted:

I rotated in four labs. The third lab that I rotated in, I chose that lab to get my $\mathrm{PhD}$ in, and then she [the PI] tells me she's low on funding. For me, that was stressful because I had to get back on the search again for a home, basically. Luckily, I was able to find a lab.

Notably, Morgan spent 4-6 months in her first lab before the PI indicated that the funding structure was not in place to sustain her. Morgan also indicated that she was looking for a PI who could "mold" her in becoming a better scientist; however, given the circumstances of her first lab, it seems that Morgan realized that there was more to lab selection than PI mentorship.

We categorized the remaining two students' stories as personal in nature, in that the mentor-mentee relationship was not a good fit in terms of research interests or personality. Amanda, a white woman and continuing-generation student, started thinking about switching labs about six months after selecting her first lab. As she discussed her thought process, she stated:

Then I realized just-I mean it's not common, but it happens. If you realize that you're not the best fit for a lab, it's mainly frowned upon, but it is acceptable to switch labs. In my situation, it actually wasn't frowned upon just because of certain incidents that had happened in the lab. My program advisor highly recommended that I leave the lab.

Amanda then did two other rotations to select a better lab fit, noting that she felt time ticking on her choice, as she was no longer a first-year student. When asked about advice she would give to students entering the lab selection process, she retrospectively reflected, "Don't worry too much about your project, and instead focus more on how you get along."

The issues with PI personality fit were mirrored by Jackson, a white man and the only first-generation student in our sample who did not find a fit in the first lab. Uniquely, Jackson indicated that he picked his first lab largely based on what was familiar. In other words, he selected a lab that appeared to have continuity with his expertise as a technician but was also looking for a PI who could be a friend. Yet, during his second-year interview, Jackson reflected:

I changed mentorship about four months ago ... Things weren't really going the way that I wanted them to go, both experiment-wise and personality-wise. It's like that clash. My old PI has a reputation for doing this. He's had six graduate students. Three out of the six have switched labs.... [When the last rotation student left the lab], he didn't really have to be chipper and nice all the time because he wasn't trying to recruit more students into his lab ... he made it quite obvious to me that the mentorship that I was originally under wasn't something that I wanted to stick around for over another five years. It [the second lab I chose] is not one that I rotated through, but it's one that I heavily considered rotating through. I sat in on lab meetings. I met with the PI several times. It just never ended up happening for me during that first set of rotations.

Taken together, these reflections indicate that students may not find "fit" with their first labs for a constellation of reasons. Among these five students, the most salient reasons were either structural (i.e., funding) or personal (i.e., PI mentorship or research alignment), and their stories illustrate how stressful and multifaceted the lab selection process can be for doctoral students.

\section{DISCUSSION}

It has long been recognized that first-year doctoral students' ability to "find a department that is a good fit for them" (Golde, 1998, p. 56) contributes to students' success throughout their 
doctoral training. In the lab-based sciences, departmental fit is primarily shaped by PIs and their labs, and students must find their places in this environment to continue their progress toward doctoral degree completion. Despite this rather sobering reality, little is known about how students determine their compatibility, or person-environment fit, with potential PIs and labs.

Overall, our results indicate that most students were fairly savvy in identifying and weighting environmental aspects important in their considerations of compatibility as they navigated available PI and lab options. In general, students closely considered their preferences for PI mentoring approach and personality. As keen observers of faculty life (Austin and McDaniels, 2006), students recognized and weighted tensions associated with selecting PIs who might relocate, and most understood the need to select a PI with funds available to support doctoral students. Students were also attentive to their own professional goals, and they actively sifted through the many available choices in the environment to place themselves in the best position for future benefits of training and employment. Finally, most students desired collegial, supportive relationships with lab mates. Thus, their perceptions of person-environment fit extensively informed their decisions regarding both the identification of relationships in which to invest (e.g., PIs, lab mates) and the navigation of their structural academic experiences (e.g., funding, research project access).

Despite all this, however, we note that students' evolving perceptions of PI and lab fit were fluid for many reasons. For example, some actively conceptualized trade-offs along various dimensions of fit (e.g., person-person, person-group, personjob). Perhaps they did not perceive a PI's mentoring approach to be fully compatible with their own mentoring preferences, but given the "perks" associated with that PI's mentorship (e.g., access to lab mates and projects), they deemed it satisfactory. Moreover, in our earlier work (Maher et al., 2019), we found that research interests of first-year doctoral students in the life sciences are notably malleable during the lab rotation period. This is perhaps how it should be, as rotations are designed to introduce students to areas of inquiry with which they may have been unfamiliar. Thus, perceptions of PI and lab fit evolved depending on, for example, students' discovery of research interests new to them. In other examples, different priorities drove PI and lab fit perceptions, such as availability of a research project that could support timely degree completion or discovery of a project that was riskier in terms of certainty of success but offered greater payoff in terms of ownership and independence. In these cases, seeking PI and lab fit was both a highly individualized process and an agentic one. Finally, students who did not secure a position in their first (or second) choice labs were forced to consider notions of fit in relation to realistic opportunities. They needed to consider their potential fit with suboptimal placements (in terms of their initial assessments); thus, identifying broader foundations for fit commonly conflicted with the need to secure financial support to continue in their doctoral programs.

\section{Weighting Fit Factors}

Earlier, we referred to Kristof-Brown and colleagues' (2005) statement: "Perceived fit ... is all done in the head of the respondents, allowing them to apply their own weighting scheme to various aspects of the environment. This permits ... salience of various dimensions to be captured in their ratings" (pp. 291292). Student response frequencies across themes and response content provided a glimpse into weighting schemes used by students in our study. In terms of response frequencies, it was clear that relationship with PI and PI mentoring style weighed heavily in students' PI selection calculations. Further, every student in our study mentioned at least one of these two factors, even when they mentioned no other factor as being involved in their PI or lab selection. In other words, these two factors (which arguably overlap to a large extent) dominated students' PI and lab selection considerations. In contrast, we were surprised to find that relatively few students considered PI professional stability. This oversight directly and negatively impacted Aaron, Erica, and Morgan, who left their first labs because of lack of PI funding. In gauging lab fit, research project and lab mates were both heavily weighted in students' considerations, but no student selected a PI and lab placement based on lab factors alone.

The content of students' responses also provided a glimpse into the weighting schemes they used. While our study purpose was exploratory in nature and designed to identify (not rate) factors, 13 students described their weighting schemes within their responses to us. Of these, eight indicated that they equally weighted the PI, research project, and/or lab mates, including Nigel, who stated, "I liked the style of the professor and I liked the research. Those are the two main areas for me [in selecting a lab]," and Aria, who recalled, "I definitely considered both the PI and the lab environment and the nature of the project."

Of interest, however, were the four students who prioritized people (PI and lab mates) over research projects. Representative comments included statements from Blake, who said, "I would argue that the people who are in the lab are almost more important than the research because if you get along with the people, you can learn to love the research," and Chelsea, who argued, "The people who are in the lab are almost more important than the research because if you get along with the people, you can learn to love the research."

Taken together, these findings suggest that participants actively weighted several factors when making PI and lab selections and that, overall, PI relationship and PI mentoring style are dominant in these weighting schemes. Further, these agentic evaluations and subsequent decisions drive students' positioning within their doctoral training experiences; the benefits of mentorship and experience with specific research projects reported by participants were realized only through their decisions regarding whether and how to engage with their environments. Accordingly, the socialization processes of knowledge acquisition, investment, and involvement were largely dependent upon students' individual assessments of fit and the potential trade-offs entailed to shape students' development as scientists.

\section{IMPLICATIONS}

The present findings examine the constellation of factors that doctoral students in the lab-based sciences weight when selecting a PI and lab, and as such, have interlocking implications for students, faculty, and programs. In regard to students, given that a doctoral advisor can "make or break a PhD student" (Lee, 2008, p. 267), it was unsurprising that all students considered at least one aspect of fit (relationship with PI, PI mentorship 
style, and PI professional stability) with their intended PIs. However, only 12 (29\%) considered all three. Given that students will likely spend at least four years-and likely moreclosely interacting with their PIs, we suggest it is in students' best interest to consider all three PI-related factors before selecting a PI. We also note that, while the three broad factors are important, for some students, more specific PI-related factors played a role, such as the PI's openness to career aspirations outside academia. Given the growing variety of careers that doctoral recipients in the biological sciences can pursue (Mathur et al., 2018), this consideration will likely become important to an increasing number of students. In terms of fit with the lab, most, but not all students $(n=28 ; 67 \%)$ considered their fit with their intended lab mates. Students will likely spend a significant amount of time with lab mates (Ferreira, 2003), and these lab mates will assuredly shape their lab experiences to a notable extent, either for better or worse (Maher et al., 2020). Thus, we posit that all students in the lab selection process should carefully and candidly consider their fit with intended lab mates as closely as they do their fit with their intended PIs.

Students are not the only ones with a critical stake in the outcome of PI and lab selection. Faculty are keenly aware of the professional, practical, and emotional costs incurred when they are not students' chosen PIs, or when they are, and the match turns sour for both parties (Maher and Ashby, 2020). As such, study findings can inform PIs' understandings of the factors that drive students' PI selection decisions. They may be able to use this knowledge to recruit and secure students who are well matched to their own dispositions, mentoring styles, and research interests. At the very least, they can use this information to make their styles, interests, and expectations explicit, so students have accurate information upon which to base their PI selection. In the long run, this transparency would stand to benefit both PIs and students.

Finally, in terms of doctoral programs in the life sciences (and beyond), the findings elucidate the need for programs to provide forums for candid and beneficial discussions between and among students and PIs around the PI and lab selection process. Our findings provide a blueprint of considerations for incoming doctoral students in the biological sciences who will engage in a process of PI and lab selection. Further, questions in our interview protocols presented in the Supplemental Material, particularly around perceptions of faculty roles and responsibilities, laboratory rotations, and PI and peer relationships, can be leveraged to create discipline- and program-specific materials to facilitate discussions around this process. Indeed, additional materials on advisor selection abound (e.g., Rose, 2003; Hineman and Semich, 2017; Sozio et al., 2017; Lipshitz, 2019), and these can also be quite useful to students, PIs, and programs that desire to infuse the PI and lab selection process with transparency and measured guidance. Essentially, we posit that the more candor and care given by and to all parties in this selection process, the more likely all parties will benefit both in the short and long term.

\section{AREAS FOR FUTURE RESEARCH AND CONCLUSION}

While the present work makes an important contribution to knowledge about doctoral students' PI and lab selection processes through the lens of person-environment fit within a socialization framework, there are multiple ways in which future research could expand on these findings. Although our results revealed limited variation in students' PI and lab selection processes based on their social identities, these differences may have been limited by the scope and sample of this project. Some recent research suggests that the expectations and relationships with PIs (and mentorship more broadly) vary by race/ ethnicity and gender (Noy and Ray, 2012; Curtin et al., 2016). Thus, there is a significant need for more research that focuses explicitly on the PI and lab selection experiences of students who identify with demographic groups historically excluded from the sciences. In taking a feminist phenomenological approach to understand women's lab rotation and selection processes, for example, recent findings suggest that women (and particularly women of color) often have to forgo research interest alignment within their lab rotations to prioritize a lab setting that is not overtly discriminatory (Wofford and Blaney, 2019). Future research examining PI and lab selection processes should consider focusing specifically on the narratives of students from historically excluded groups in the sciences, as doing so may shed light on specific (dis)advantages upheld in the structures of doctoral education programs.

It would also be quite valuable to understand whether both the incidence and resolution of situations of "no fit" are similar across student groups. While the findings from this study were inconclusive in this regard, some research notes that women and historically excluded students have less-positive experiences in their doctoral programs (Gildersleeve et al., 2011; Sallee, 2011; Gardner, 2013; Ramirez, 2017; Miller and Roksa, 2020). This may imply both the greater likelihood of these students not finding a good fit as well as a lower probability that a situation of poor fit will be positively resolved. Productively resolving a situation of no fit involves finding a new lab, which implies a certain amount of institutional (e.g., departmental) involvement in terms of both acknowledging that the original situation is not tenable and developing a solution. Whether departments facilitate a renewed search for a lab equitably across sociodemographic groups is a worthwhile question, especially in the instances when a lack of fit involves not getting along with the PI as opposed to a financial necessity (i.e., PI does not get a grant).

An important area for future research is understanding the short- and long-term consequences of not finding fit in the lab and PI selection process, and whether and how those may vary across students from different sociodemographic groups. All students who did not find an initial lab fit in this study found another lab in which to do their training. However, the consequences of not finding fit are significant. As we noted earlier, first-year students who do not find a PI and lab fit usually leave their doctoral programs (Maher et al., 2020). Some intended to re-enroll in another doctoral program, but many chose to permanently close the door on doctoral education. We found that second-year students who realized that their selected PIs and/or labs were not a good fit also left early, often "mastering out."

While our work in this area was limited to the first two years of doctoral training, had our sample also included students in their final years of doctoral training, we might have found different perspectives about how these students not only chose labs, but also chose to continue (or not) in these same labs throughout their doctoral tenure. We believe that it is likely that students 
who move labs in their third year or beyond may extend time to degree and/or experience negative degree impacts or diminished career prospects. Given high attrition from doctoral programs (Cassuto, 2013; Council of Graduate Schools, 2008) and persistent questions about the demographic diversity of science, technology, engineering, and mathematics disciplines (Okahana et al., 2016), understanding the patterns and consequences of finding (or not finding) PI and lab fit have important implications for doctoral education and future scientists.

Additional directions for future research include expanding the diversity of the institutional contexts and disciplines to tease out potential variations in students' ranking of key PI-lab selection elements noted in this study across varying lab-based disciplines (e.g., chemistry, physics) and institutional contexts (e.g., comprehensive universities, minority-serving institutions). Different combinations or valuing of key selection elements may be represented within varying disciplinary and institutional contexts with unique disciplinary expectations and levels of resources. Further, additional research could explore the nature, extent, and implications of students' not finding strong fit and merely "satisficing" during their doctoral training (e.g., finding a strong fit with a PI but not with that PI's lab, or vice versa). In these cases, it would be valuable to know how students optimize their decisions when they do not realize all of their preferences.

Finally, we note that research on the practice of rotations is sparse, despite their use in doctoral training across a range of lab-based disciplines. Investigating whether or how students' doctoral experiences and outcomes vary depending on whether students are paired with their PIs upon program initiation or through the rotation process would shed light on the nature and extent of benefits, if any, that accrue to students through rotation participation. Students who rotate spend a significant portion of the first year of doctoral training in lab rotations, thus delaying their entry into the labs in which they will conduct their dissertation work. Further, PIs spend time and effort training students with whom they will ultimately not be paired, while institutions spend resources to support the rotation process (Maher and Ashby, 2020). Given these considerations, the question of the nature and extent of the benefits of lab rotations is vital to shaping the next generation of scientists.

\section{ACKNOWLEDGMENTS}

We gratefully acknowledge the support of the National Science Foundation. This material is based upon work supported under awards 1760894, 1431234, and 1431290. Any opinions, findings, and conclusions or recommendations expressed in this material are those of the authors and do not necessarily reflect the views of the NSF.

\section{REFERENCES}

Arnaud, C. H. (2015, October 19). Oklahoma revamps graduate program. Chemical and Engineering News. Retrieved July 3, 2020, from https://chemgradeddotcom. files.wordpress.com/2016/01/cen20151019 -dl_pp38-39.pdf

Austin, A. E. (2009). Cognitive apprenticeship theory and its implications for doctoral education: A case example from a doctoral program in higher and adult education. International Journal for Academic Development, $14,173-183$

Austin, A. E., \& McDaniels, M. (2006). Preparing the professoriate of the future: Graduate student socialization for faculty roles. In Smart, J. C. (Ed.), Higher education: Handbook of theory and research (Vol. 21, pp. 397456). Secaucus, NJ: Springer.
Baker, V. L., \& Pifer, M. J. (2015). Antecedents and outcomes: Theories of fit and the study of doctoral education. Studies in Higher Education, 40, $296-310$.

Barres, B. A. (2013). How to pick a graduate advisor. Neuron, 80(16), 275-279.

Campbell, R. A. (2003). Preparing the next generation of scientists: The social process of managing students. Social Studies of Science, 33, 897-927.

Canver, M. C. (2012). Graduate school: The problem of choice. IEEE Pulse, Retrieved February 19, 2018, from https://ieeexplore.ieee.org/stamp/ stamp.jsp?arnumber $=6244926$

Cassuto, L. (2013). Ph.D. attrition: How much is too much? Chronicle of Higher Education, 59, A27.

Conefrey, T. (1997). Gender, culture and authority in a university life sciences laboratory. Discourse \& Society, 8, 313-340.

Conti, A., \& Liu, C. C. (2015). Bringing the lab back in: Personnel composition and scientific output at the MIT Department of Biology. Research Policy, 44, 1633-1644.

Corbin, J., \& Strauss, A. (2015). Basics of qualitative research (4th ed.). Thousand Oaks, CA: Sage.

Council of Graduate Schools. (2008). Ph.D. completion and attrition: Analysis of baseline demographic data from the Ph.D. Completion Project Retrieved July 3, 2020, from www.phdcompletion.org/information/ publications.asp

Curtin, N., Malley, J., \& Stewart, A. J. (2016). Mentoring the next generation of faculty: Supporting academic career aspirations among doctoral students. Research in Higher Education, 57, 714-738.

Dasgupta, S., Symes, K., \& Hyman, L. (2015). Leading change: Curriculum reform in graduate education in the biomedical sciences. Biochemical and Molecular Biology Education, 43, 126-132.

Dundar, H., \& Lewis, D. R. (1998). Determinants of research productivity in higher education. Research in Higher Education, 39, 607-631.

Feldman, K. A., Smart, J. C., \& Ethington, C. A. (2004). What do college students have to lose? Exploring the outcomes of differences in person-environment fits. Journal of Higher Education, 75, 528-555

Feldon, D. F. (2020). Implications of measurement issues for advancing the socialization framework. In DeAngelo, L., \& Weidman, J. C. (Eds.), Socialization in higher education and the early career: Theory, research and application (pp. 287-310). New York: Springer International.

Feldon, D. F., Litson, K., Jeong, S., Blaney, J., Kang, J., Miller, C., ... \& Roksa, J. (2019). Postdocs' lab engagement predicts trajectories of Ph.D. students' skill development. Proceedings of the National Academy of Sciences USA, 116(42), 20910-20916

Feldon, D. F., Peugh, J., Maher, M. A., Roksa, J., \& Tofel-Grehl, C. (2017). Effort-to-credit gender inequities of first-year PhD students in the biological sciences. CBE-Life Sciences Education, 16(1), ar4.

Ferreira, M. (2003). Gender issues related to graduate student attrition in two science departments. International Journal of Science Education, 25 969-989.

Fuhrmann, C. N., Halme, D. G., O'Sullivan, P. S., \& Lindstaedt, B. (2011) Improving graduate education to support a branching career pipeline: Recommendations based on a survey of doctoral students in the basic biomedical sciences. CBE-Life Sciences Education, 10, 239-249.

Gardner, S. K. (2013). The challenges of first-generation doctoral students New Directions for Higher Education, 163, 43-54.

Gibbs, K. D., \& Griffin, K. A. (2013). What do I want to be with my Ph.D.? The roles of personal values and structural dynamics in shaping the career interests of recent biomedical science Ph.D. graduates. CBE-Life Sciences Education, 12, 711-723.

Gildersleeve, R. E., Croom, N. N., \& Vasquez, P. L. (2011). Am I going crazy?! A critical race analysis of doctoral education. Equity $\&$ Excellence in $E d-$ ucation, 44, 93-114.

Glaser, B. G. (1965). The constant comparative method of qualitative analysis Social Problems, 12, 436-445.

Golde, C. M. (1998). Beginning graduate school: Explaining first-year doctoral attrition. In Anderson, M. S. (Ed.), The experience of being in graduate school: An exploration (pp. 55-64). San Francisco, CA: Jossey-Bass.

Gopaul, B. (2016). Applying cultural capital and field to doctoral student socialization. International Journal for Researcher Development, 7, $46-62$. 
Griffin, K. A., Baker, V., O'Meara, K., Nyunt, G., Robinson, T., \& Staples, C. L. (2018). Supporting scientists from underrepresented minority backgrounds: Mapping developmental networks. Studies in Graduate and Postdoctoral Education, 9, 19-37.

Hineman, J. M., \& Semich, G. (2017). Choosing a dissertation advisor: Challenges and strategies for doctoral students. Inquires Journal, 9(3). Retrieved July 3, 2020, from www.inquiriesjournal.com/a?id=1588

Holland, J. L. (1959). A theory of vocational choice. Journal of Counseling Psychology, 6, 35-45.

Holland, J. L. (1966). The psychology of vocational choice. Waltham, MA: Blaisdell.

Holland, J. L. (1997). Making vocational choices: A theory of vocational personalities and work environments (3rd ed.). Odessa, FL: Psychological Assessment Resources.

Holley, K. (2010). Doctoral student socialization in interdisciplinary fields. In Gardner, S. K., \& Mendoza, P. (Eds.), On becoming a scholar: Socialization and development in doctoral education (pp. 97-112). Sterling, VA: Stylus Publishing.

Holley, K. A. (2011). A cultural repertoire of practices in doctoral education. International Journal of Doctoral Studies, 6, 79-95.

Hunter, A-B., Laursen, S. L., \& Seymour, E. (2007). Becoming a scientist: The role of undergraduate research in students' cognitive, personal, and professional development. Science Education, 91, 36-74.

Jansen, K. J., \& Kristof-Brown, A. L. (2006). Toward a multidimensional theory of person-environment fit. Journal of Managerial Issues, 18, 193-212.

Jeong, S., Litson, K., Blaney, J., \& Feldon, D. F. (2020). Shifting gears: Characteristics and consequences of latent class transitions in doctoral socialization. Research in Higher Education. Retrieved July 3, 2020, from https://doi.org/10.1007/s11162-019-09583-7

Joy, S., Liang, X., Bilimoria, D., \& Perry, S. (2015). Doctoral advisor-advisee pairing in STEM fields: Selection criteria and impact of faculty, student and department factors. International Journal of Doctoral Studies, 10, $343-363$.

Juliano, R. L., \& Oxford, G. S. (2001). Critical issues in Ph.D. training for biomedical scientists. Academic Medicine, 76, 1005-1012.

Kristof-Brown, A. L., \& Billsberry, J. (2013). Fit for the future. In Kristof-Brown, A. L., \& Billsberry, J. (Eds.), Organizational fit: Key issues and new directions (pp. 1-18). Oxford: Wiley-Blackwell.

Kristof-Brown, A. L., \& Li, C. S. (2017). Person-environment fit. In Griffin, R. (Ed.), Oxford Bibliographies in Management Science. Oxford: Oxford University Press. doi: 10.1093/OBO/9780199846740-0117

Kristof-Brown, A. L., Li, C. S., \& Schneider, B. (2018). Fitting in and doing good: A review of person-environment fit and organizational citizenship behavior research. In Podsakoff, P. M., Mackenzie, S. B., \& Podsakoff, N. P. (Eds.), The Oxford handbook of organizational citizenship behavior (pp. 353-370). Oxford University Press.

Kristof-Brown, A. L., Zimmerman, R. D., \& Johnson, E. C. (2005). Consequences of individuals' fit at work: A meta-analysis of person-job, person-organization, person-group, and person-supervisor fit. Personnel Psychology, 58, 281-342.

Kyvik, S., \& Smeby, J. (1994). Teaching and research. The relationship between the supervision of graduate students and faculty research performance. Higher Education, 28, 227-239.

Lane, A. K., Hardison, C., Simon, A., \& Andrews, T. C. (2019). A model of the factors influencing teaching identity among life sciences doctoral students. Journal of Research in Science Teaching, 56, 141-162.

Lee, A. (2008). How are doctoral students supervised? Concepts of doctoral research supervision. Studies in Higher Education, 33, 267-281.

Lee, S., \& Bozeman, B. (2005). The impact of research collaboration on scientific productivity. Social Studies of Science, 35, 673-702.

Lipshitz, R. (2019). On choosing a thesis mentor. Notices of the American Mathematical Society, 66, 191-193.

Maher, M., Wofford, A., Roksa, J., \& Feldon, D. F. (2020). Exploring early exits: Doctoral attrition in the biomedical sciences. Journal of College Student Retention: Research, Theory, \& Practice, 22(2), 186-204

Maher, M., Wofford, A., Roksa, J., \& Feldon, D. F. (2019). Doctoral student experiences in biological sciences laboratory rotations. Studies in Graduate and Postdoctoral Education, 10, 69-82.
Maher, M. A., \& Ashby, M. T. (2020). Practical realities, hidden costs, and twoway street benefits: Faculty experiences hosting laboratory rotation students. Paper prepared for presentation at: Annual meeting of the American Educational Research Association (San Francisco, CA) [conference cancelled].

Maher, M. A., Gilmore, J. A., Feldon, D. F., \& Davis, T. E. (2013a). Cognitive apprenticeship and the supervision of science and engineering research assistants. Journal of Research Practice, 9, arM5.

Maher, M. A., Timmerman, B. E., Feldon, D. F., \& Strickland, D. (2013b). Factors affecting the occurrence of faculty-doctoral student coauthorship. Journal of Higher Education, 84, 121-143.

Malone, K. R., \& Barabino, G. (2009). Narrations of race in STEM research settings: Identity formation and its discontents. Science Education, 93(3), 485-510.

Mathur, A., Cano, A., Kohl, M., Muthunayake, N. S., Vaidyanathan, P., Wood, M. E., \& Ziyad, M. (2018). Visualization of gender, race, citizenship and academic performance in association with career outcomes of 15-year biomedical doctoral alumni at a public research university. PLOS ONE, 13(5), 1-16. doi: 10.1371/journal.pone.0197473

Mendoza-Denton, R., Patt, C., Fisher, A., Eppig, A., Young, I., Smith, A., \& Richards, M. A. (2017). Differences in STEM doctoral publication by ethnicity, gender and academic field at a large public research university. PLOS ONE. https://doi.org/10.1371/journal.pone.0174296

Merriam, S. B. (2002). Qualitative research in practice: Examples for discussion and analysis. San Francisco, CA: Jossey-Bass.

Merriam, S. B. (2009). Qualitative research: A guide to design and implementation. San Francisco, CA: Jossey-Bass.

Miller, C., \& Roksa, J. (2020). Balancing research and service in academia: Gender, race, and laboratory tasks. Gender \& Society, 34, 131-152. doi 10.1177/0891243219867917

National Academies of Science, Engineering, and Medicine (NASEM). (2018). Graduate STEM education for the 21st century. Washington, DC: National Academies Press. https://doi.org/10.17226/25038.

National Science Foundation. (2014). Higher education research and development survey (HERDS). Retrieved February 19, 2018 from, www.nsf .gov/statistics/srvyherd

Nauta, M. M. (2010). The development, evolution, and status of Holland's theory of vocational personalities: Reflections and future directions for counseling psychology. Journal of Counseling Psychology, 57, 11-22.

Noy, S., \& Ray, R. (2012). Graduate students' perceptions of their advisors: Is there systematic disadvantage in mentorship? Journal of Higher Education, 83, 876-914.

Okahana, H., Allum, J., Felder, P. P., \& Tull, R. G. (2016). Implications for practice and research from Doctoral Initiative on Minority Attrition and Completion (CGS data sources PLUS no. 16-01). Washington, DC: Council of Graduate Schools.

Parsons, F. (1909). Choosing a vocation. Boston, MA: Houghton Mifflin.

Pervin, L. A. (1968). Performance and satisfaction as a function of individualenvironment fit. Psychological Bulletin, 69, 56-68.

Posselt, J. R. (2018). Rigor and support in racialized learning environments: The case of graduate education. New Directions for Higher Education, $181,59-70$.

Ramirez, E. (2017). Unequal socialization: Interrogating the Chicano/Latino(a) doctoral education experience. Journal of Diversity in Higher Education, $10,25-38$

Riggers-Piehl, T. A., \& Lehman, K. J. (2016). Modeling the relationship between campus spiritual climate and sense of belonging for Christian, Muslim and Jewish students. Religion and Education, 43, 247-270.

Roksa, J., Feldon, D., \& Maher, M. (2018a). First-generation students in pursuit of the Ph.D.: Comparing socialization experiences and outcomes to continuing-generation peers. Journal of Higher Education, 89, 728-752. doi: /10.1080/00221546.2018.1435134

Roksa, J., Jeong, S., Feldon, D., \& Maher, M. (2018b). Socialization experiences and research productivity of Asians and Pacific Islanders: "Model minority" stereotype and domestic vs. international comparison. Research in the Sociology of Education, 20, 155-179. doi: /10.1108/S1479 $-353920180000020007$

Rose, G. L. (2003). Enhancement of mentor-selection using the ideal mentor scale. Research in Higher Education, 44, 473-494. 
Sallee, M. W. (2011). Performing masculinity: Considering gender in doctoral student socialization. Journal of Higher Education, 82, 187-216.

Schneider, B. (1987). The people make the place. Personnel Psychology, 40, 437-453

Sozio, S. M., Chan, K. S., \& Beach, M. C. (2017). Development and validation of the medical student scholar-ideal mentor scale (MSS-IMS). BMC Medical Education, 17(1), 132. doi: 10.1186/s12909-017-0969-1

Strauss, A., \& Corbin, J. (1998). Basics of qualitative research (2nd ed.). Thousand Oakes, CA: Sage.

Su, R., Murdock, C., \& Rounds, J. (2015). Person-environment fit. In Hartung, P. J., Savickas, M. L., \& Walsh, W. B. (Eds.), APA handbook of career intervention, Vol. 1, Foundations (APA handbooks in psychology, pp. 81-98). Washington, DC: American Psychological Association.

Sweitzer, V. (2009). Towards a theory of doctoral student professional identity development: A developmental networks approach. Journal of Higher Education, 80, 1-33.

Szelényi, K., Bresonis, K., \& Mars, M. M. (2016). Who am I versus who can I become? Exploring women's science identities in STEM Ph.D. programs. Review of Higher Education, 40, 1-31.
Tierney, W. G., \& Rhodes, R. A. (1994). Enhancing promotion, tenure, and beyond: Faculty socialization as a cultural process (ASHE-ERIC Higher Education Report No. 93-6). Washington, DC: The George Washington University, School of Education and Human Development.

Walker, G. E., Golde, C., Jones, L., Conklin Bueschel, A., \& Hutchings, P. (2008). The formation of scholars: Rethinking doctoral education for the twenty-first century. San Francisco, CA: Jossey-Bass.

Weidman, J. C., Twale, D. J., \& Stein, E. L. (2001). Socialization of graduate and professional students: A perilous passage? ASHE-ERIC Higher Education Report 28, no. 3. Washington, DC: Association of the Study of Higher Education.

Wofford, A., \& Blaney, J. (2019, November 14-16). Shaping the social(ization) of scientific labs: A longitudinal study of women's doctoral experiences in STEM lab rotations. Paper presented at: Association for the Studies of Higher Education 44th Annual Meeting (Portland, OR).

Ynalvez, M. A., Ynalvez, R. A., \& Ramírez, E. (2017). Mentor-mentee interaction and laboratory social environment: Do they matter in doctoral students' publication productivity? Biochemistry and Molecular Biology Education, 45, 130-144 